\title{
Leminski e a inversão do pensamento clássico cartesiano
}

\author{
Adriel Fonteles de Moura $^{74}$
}

\section{Este mundo é o lugar do desvario, a justa razão aqui delira ${ }^{75}$}

\begin{abstract}
Resumo: Apresenta-se, neste trabalho, uma perspectiva de leitura que o escritor curitibano Paulo Leminski tem sobre a obra do filósofo René Descartes. No programa filosófico de Descartes, o pensamento moderno era a base de compreensão em relação a totalidade da natureza. Por outro lado, Leminski, na sua obra, experimenta literariamente a intersecção do pensamento moderno com um mundo totalmente diferente do contexto europeu. Portanto, este artigo tem por objetivo explicar como este paradigma moderno se dissolve e perde a sua efetividade no contexto do mundo tropical.
\end{abstract}

Palavras-chave: Leminski. Descartes. Filosofia Moderna. Estética.

\begin{abstract}
This paper presents a reading perspective that the writer Paulo Leminski, from Curitiba - Brasil, sustains about he work of the philosopher René Descartes. In Descartes' philosophical program, the modern thought was the basis of the comprehension of the totality of nature. On the other hand, Leminski, trough his writings experiments literarily the intersection of modern thought and a world which is totally different from the European context. Therefore, this article aims to explain how this modern paradigm dissolves itself and loses its effectiveness in the context of tropical world.
\end{abstract}

Keywords: Leminski. Descartes. Modern Philosophy. Aesthetics.

Submetido em: janeiro de 2016.

Aprovado em: março de 2016.

\section{Introdução}

O âmbito e a temática de pesquisa constituinte do presente trabalho é investigar, de maneira especulativa, como o pensamento cartesiano se dissolve na principal obra literária do escritor curitibano Paulo Leminski: Catatau. A dissolução do pensamento cartesiano ocorre, no interior da obra, pela realização de uma situação hipotética: e se René Descartes tivesse vindo ao Brasil com as tropas de Maurício de Nassau? Ora, mesmo que esta situação jamais ocorrido de fato (ou quase), a discussão filosófica que o livro propõe se perfaz na inefetividade da ontologia cartesiana em entender e compreender a totalidade de um mundo completamente estrangeiro, cujos fenômenos e

\footnotetext{
${ }^{74}$ Acadêmico Filosofia UFPR - E mail: ladriel.fonteles@yahoo.com

75 Paulo Leminski, Catatau: um romance ideia, São Paulo: Editora lluminuras, 2015, p. 19.
} 
acontecimentos naturais oriundos de uma terra estrangeira permanece uma novidade ao paradigma moderno europeu. Este mundo será chamado aqui de mundo dos trópicos. Neste artigo, a intenção é demonstrar como alguns elementos da filosofia cartesiana representando o grande advento do homem europeu na modernidade - entram em conflito com este mundo ou, em outras palavras, com uma natureza impossível de ser apreendida devido a riqueza e a multiplicidade de acontecimentos correntes nesta obra de Paulo Lemiski.

A primeira parte deste trabalho se justifica em explicar, paralelo ao Catatau, a relação da ideologia europeia com um mundo diverso. Neste caso, trata-se de expor brevemente o eixo histórico da obra, como as diretrizes do colonialismo e a recepção brasileira da modernidade europeia. Em seguida, transpassa-se esta discussão na demonstração dos precedentes ontológicos da obra cartesiana, tais como O Discurso do Método $^{76}$ e Princípios de Filosofia ${ }^{77}$, para sedimentar as menções ao filósofo no Catatau. Finalmente, o último tópico deste trabalho procura-se expor a importância de duas atitudes recorrentes de Cartesius: o uso da luneta e de ervas alucinógenas. A primeira atitude representa o distanciamento do fenômeno pela abstração conceitual e a segunda, ao contrário, a aproximação fenomênica de Cartesius com o desconhecido e estranho mundo tropical ao pensamento clássico cartesiano.

Todavia, não é objeto deste trabalho apresentar uma hipótese para esgotar a interpretação da obra, filosófica e literariamente. O conjunto de hipóteses levantadas nos tópicos abaixo tem como intenção explicar o porquê do pensamento cartesiano não bastar para mensurar a natureza, principalmente quando esta se refere a um mundo cultural e intelectualmente distanciado do mundo europeu. As chaves de leitura para a obra são múltiplas e compreendem várias áreas do conhecimento, desde mitologia, perpassando por geometria e também a história. Portanto, em estrito caso, este trabalho tem como fim apontar as adversidades do próprio pensamento ao se encontrar fora de lugar, de acordo com que diz o crítico literário Roberto Schwarz. ${ }^{78}$

\section{1) O mundo europeu no mundo dos trópicos}

76 René Descartes, Discurso do Método in: Os pensadores. Trad.: Enrico Corvisieri. São Paulo: Nova Cultural, 1999.

77 René Descartes, Princípios da Filosofia. Trad.: João Gama. Lisboa: Edições 70, 2003.

78 Roberto Schwarz, Ideias fora do lugar in: Ao Vencedor, as Batatas. São Paulo: Duas Cidades, 1992. 
O Brasil colonial, contemporâneo ao auge da modernidade europeia, se apresenta como uma disjunção do pensamento sistemático científico que revolucionou desde a intelectualidade até as relações de trabalho. No Brasil colonial, o pensamento clássico científico - iluminista, progressista e humanista -, não se consolidou aqui sem sofrer diversas subversões e adaptações a um mundo completamente atípico para os europeus que estavam protagonizando e participando da colonização, em meados do século XVII; a marca deste conjunto de readaptações se institui pelo desmantelamento progressivo dos princípios estabelecidos e sistemáticos que caracterizavam a aura da modernidade, em todos os sentidos. No que diz respeito às relações de trabalho, o modus operandi que as conjuravam neste mundo dos trópicos era ainda a escravidão, que representava a ápice negativo em relação as ideias liberais que estavam surgindo no velho continente, fruto do novo pensamento que estava em expansão por toda a Europa.

Apresentada esta disparidade entre a sociedade escravista e as ideias modernas que representavam o liberalismo europeu, diz Schwarz:

(...) o universalismo era ideologia na Europa também; mas lá correspondiam às aparências, encobrindo o essencial - a exploração do trabalho. Entre nós, as mesmas ideias seriam falsas num sentido diverso, por assim dizer, original",79

Tendo como hipótese de que a exploração escravista, própria das relações de trabalho constituídas no Brasil colonial, seja uma parte antagônica do ideal moderno liberal europeu, como conceber o pensamento brasileiro como unidade própria e desgarrada do ideário do velho continente? A resposta é simples dada a complexidade da pergunta: não há, no nosso mundo dos trópicos, uma unidade de pensamento sumamente própria. Conceber o pensamento enquanto pensamento é uma atividade estritamente unificada nas tradições intelectuais do velho continente. Tentar adaptar o exercício racional a estas terras implicaria no enviesamento da razão. Leminski, no seu romance experimental Catatau, concretiza esta perda da razão em terras tupiniquins, cujas novas ideias europeias e liberais não se encaixam no lugar pelo qual as relações de trabalhos e a constituição da cultura são ultrapassadas, tendo como referente o continente europeu.

A razão e a cultura europeia (principalmente batava, nas invasões holandesas), encontra

79 Roberto Schwarz, Ideias fora do lugar, p. 2. 
as suas contradições e disparates no Brasil, desde a dificuldade (e, por assim dizer, impossibilidade) dos holandeses em ensinar a língua aos povos nativos até a adaptação deles em operar diante de uma terra amplamente desconhecida. Esta disjunção encontrada na Europa nos trópicos é percebida por Schwarz:

\begin{abstract}
Em suma, se insistimos no viés do que o escravismo e o favor introduziram nas ideias do tempo, não foi para descartar, mas para descrevê-las enquanto enviesadas - fora do centro em relação à exigência que elas mesmos propunham, e reconhecivelmente nossas, nessa mesma qualidade. Assim, posto de parte o raciocínio sobre causas, resta na experiência aquele "desconcerto" que foi o nosso ponto de partida: a sensação que o Brasil dá de dualismo e factício contrastes rebarbativos, desproporções, disparates, anacronismos, contradições e o que for - combinações que o Modernismo, o Tropicalismo e a Economia Política nos ensinaram a considerar. ${ }^{80}$
\end{abstract}

O obliquamento das ideias constituídas pelo dualismo típico da história intelectual brasileira parte da concepção de uma ideologia liberal que foi-se constituindo no homem branco e livre nas colônias tupiniquins. Este homem branco e livre, paradoxalmente, possuía uma sutil dependência da metrópole para satisfazer interesses materiais e intelectuais ${ }^{81}$ com o mundo central e hegemônico. No entanto, o empréstimo de dispositivos culturais e intelectuais advindos do velho continente não faz do Brasil uma extensão da Europa; muito pelo contrário, estar em terras estrangeiras - em todos os sentidos - mantém a efetividade do pensamento branco difícil de se realizar em sua plenitude, tal como a grande complicação em que os batavos tiveram em se adaptar nestas terras. Todavia, os portugueses foram mais amistosos em permitir a homogeneização e a aproximação do mundo do centro com o mundo periférico. Portanto, o mundo europeu e branco, com todo o seu ideário intelectual e cultural, não se fundiu com o mundo dos trópicos por completo, mas também não ficaram indissociavelmente separados; o ideário europeu sofre, então, uma distorção atemporal dos seus elementos, como é o caso da relação entre os nomes e definições tentando atribuir sentido aos referentes elementos naturais dos trópicos.

\title{
2) A primazia ontológica da natureza em relação ao homem
}

A obra Catatau, concluída em 1975 pelo poeta paranaense Paulo Leminski,

80 Roberto Schwarz, Ideias fora do lugar, p. 9.

81 Cf. Roberto Schwarz, Ideias fora do lugar, p. 5: “O favor é, portanto, o mecanismo através do qual se reproduz uma das grandes classes da sociedade, envolvendo também outra, a dos que têm". 
revela a relação entre dois elementos que se fundem contraditoriamente. $\mathrm{O}$ primeiro elemento é a racionalidade europeia e abstrata, embasada no substancialismo cartesiano no ápice da modernidade. O segundo elemento repousa no âmbito do concreto, do fenomênico e do sensível - hipostasiado pela confusão e balbúrdia da América dos trópicos, inexplicável pelo conceito racional moderno de natureza. Fruto destes dois elementos contrários, o Catatau registra o conflito da natureza europeia no pensamento ou, melhor dizendo, da inefetividade do pensamento em compreender a heterogeneidade e diversidade do mundo tropical, com a sua fauna e flora tão inquieta que as categorias de uma epistemologia florescente torna-se rasa. Desta maneira, constitui-se o Catatau basicamente, obra subtitulada por Leminski como Romance-ideia.

A ideia cartesiana, consequência de uma operação do espírito pelo pensamento em compreender a substância extensa é, sui generis, clara e distinta. No concreto mundo dos trópicos, cujo pensamento se perde em meio à profusão de disformidades que se apresenta nas florestas brasileiras e nos animais que habitam nelas, a clareza e distinção das ideias não se conforma à matéria deste mundo ${ }^{82}$. Veja-se, de passagem, que o Catatau é um romance ora poético, ora prosaico, cujo estilo é experimental. Não há um enredo claro que segue uma cadeia de fatos no interior da obra. Por fim, o desenvolvimento da obra reflete mimeticamente o mundo dos trópicos e o deslocamento confuso do sujeito pensante entre a fauna e flora totalmente estrangeira e diversificada. Este deslocamento confuso é representado, nas palavras do próprio Leminski, sem mapas, cujas experiências alucinógenas é o princípio motor para a locomoção deste sujeito pensante ${ }^{83}$.

Uma das epígrafes presentes no Catatau é do matemático e naturalista alemão George Marcgravf, um dos responsáveis pelas primeiras publicações científicas sobre a constituição geográfica e biológica do Brasil, contemporâneo ao René Descartes, do qual a variante latinizada pelo Leminski de seu nome é Renatus Cartesius ${ }^{84}$. Voltando à epígrafe primeira de Leminski, nela há uma descrição fisiológica de uma ave que parece

82 "Descartes, exímio dos mais hábeis manejos de ausência, fraqueja. E a exigência de ideias claras e distintas acaba tornando-se incômoda e até dolorosa. Os esquemas 'clássicos' são camisas de força estourando. (...). Leminski dá conta de um outro fracasso: pensar o Brasil em pensamento Europeu". Trecho retirado da resenha crítica de Antônio Risério em seu ensaio Catatau: cartesanato em : Paulo Leminski, Catatau, p. 237.

83“Me nego a ministrar clareiras para a inteligência deste catatau que, por oito anos, agora, passou muito bem sem mapas. Virem-se" (Paulo Leminski, Catatau, p.12).

84“ergo sum, aliás, Ego sum Renatus Cartesius, cá perdido, aqui presente, neste labirinto de enganos deleitáveis, vejo o mar, vejo a baía e vejo as naus" (Paulo Leminksi, Catatau, p. 15). 
ser oriunda de terras estrangeiras, dada a monstruosidade que Marcgravf confere em seu registro: "A cabeça, pescoço, ventre, asas, dorso e parte superior das pernas não eram cobertas de penas mas de pelos pretos de meio dedo de comprimento, um pouco claras debaixo do ventre e garganta; em resumo, um pinto totalmente monstruoso" 85 . No decorrer das caminhadas de Cartesius, confuso e alucinado pela imensidão da natureza inconcebível dos trópicos, a atenção é muito voltada aos animais. Neste caso, conceber os animais como meros seres autômatos não dotados de capacidade raciocinativa é insuficiente diante da relação estonteante entre Cartesius e os animais no mundo dos trópicos ${ }^{86}$. Percebe-se, pois, uma cisão radical entre homem e animal. Não obstante, diante deste fato, a cisão é outra; não demonstra uma superioridade do homem em relação aos animais pela asserção da razão, entretanto, justamente o contrário, o qual o pensamento clássico não surte nenhuma efetividade, já que este

(...) não dá muita atenção ao animal, à criança, ao primitivo e ao louco. Lembramos que Descartes não via o animal nada além de uma soma de rodas, alavancas, molas, enfim, de uma máquina: quando não era uma máquina, o animal era, no pensamento clássico, um esboço do homem, e muitos entomologistas não hesitaram em projetar nele as características principais da vida humana. ${ }^{87}$

A dicotomia, portanto, entre homem e animal não aparece eliminada, mas assume outra forma do qual há a necessidade natural da dissolução da relação entre sujeito e objeto à moda clássica.

Sendo assim, o objetivo central - em termos filosóficos - do Catatau é suprimir a noção cartesiana do "homem rematado". Dominação e indiferença à natureza exterior ao homem são condições capitais para o livre exercício do direito divino da razão, conferido exclusivamente a este modelo de homem ${ }^{88}$. Está claro que o homem

85 George Marcgravf, Historia Naturalis; História das Aves, Lib.V, Cap. XVI in: Paulo Leminski, Catatau, p.13

86 Referência, em caráter afirmativo negativo, à passagem In primis cogitationibus circa generationem animalium, de his omnibus non cogitavi que tem como tradução aproximada "Em primeiro lugar, os pensamentos sobre a geração animal, todas estas coisas não pensam" (Paulo Leminski, Catatau, p. 17).

87 Maurice Merleau-Ponty, Conversas - 1948, trad. Fábio Landa \& Eva Landa. São Paulo: Martins Fontes, 2004, p.33

88 "Por que, então, tantos escritores clássicos mostram indiferença com respeito aos animais, às crianças, aos loucos, aos primitivos? É que estão convencidos de que existe um homem rematado, destinado a ser "senhor e possuidor" da natureza, como dizia Descartes, capaz, assim, por princípio, de penetrar até o ser das coisas, de constituir um conhecimento soberano, de decifrar todos os fenômenos e não somente os de natureza física, mas ainda aqueles que a história e a sociedade humana nos mostra como explicá-los por suas causas e finalmente de encontrar , em algum acidente de seu corpo, a razão das anomalias que mantém a criança, o primitivo, o louco, o animal, à margem da verdade" (Maurice Merleau-Ponty, Conversas - 1948, p.35). 
rematado, crente em possuir e apreender em sua totalidade a natureza tropical brasileira, acaba por ser engolfado na ordem dos fenômenos naturais inapreensíveis. Em uma passagem, a citar, do Catatau, Leminski parece identificar o ato de comer animais em criar, pelo exercício do pensamento, um conceito de animal. Só que na mesma passagem Cartesius demonstra a sua confusão ao tentar tal tarefa, já que "Comer esses animais há de perturbar singularmente as coisas do pensar" ${ }^{\prime 29}$. Não basta esta confusão e perturbação, mas também ocorre a inversão da relação estabelecida pelo pensamento clássico, isto é, a asserção da natureza sobre o "homem rematado", tal como mostra a passagem: "Olho, penso esse bicho, o bicho me pisa na cabeça, o ventre pesa a carne, carcomido" $"$. Portanto, eis como o Catatau, mesmo sendo extemporâneo ao pensamento clássico cartesiano, dissolve a noção do "homem rematado".

A segunda epígrafe, de fonte desconhecida, remete ao filósofo escolástico francês Nicolas d'Autrecourt (1299 - 1369), a saber:

O universo, reduzido a uma pura multiplicidade fenomenal, não tem mais consistência para se afirmar em si, como um objeto distinto do sujeito que conhece. Ele evapora, por assim dizer, em puras aparências engendradas misteriosamente a partir das virtualidades do objeto. ${ }^{91}$

Este filósofo, anterior à tradição moderna de Descartes, antecipa uma perspectiva filosófica que tem como contrapartida o pensamento clássico em relação à totalidade das coisas. Para Autrecourt, o universo permanece tão somente na ordem dos fenômenos ou da experiência. Para Descartes, mesmo que o homem tenha um espírito limitado, ele é capaz de apreender racionalmente grande parte dos fenômenos, pela divina razão atribuída a este ${ }^{92}$. Esta apreensão racional dos fenômenos, segundo Descartes, ocorre pela dedução das causas sobre o efeito, neste caso, as experiências ou os fenômenos ${ }^{93}$.

Em termos ontológicos, dentro da filosofia de Descartes, é de suma necessidade fazer uma digressão com fins de análise de algumas suposições advindas da filosofia

\footnotetext{
89 Paulo Leminski, Catatau, p. 17.

90 Paulo Leminski, Catatau, p. 17.

91 Paulo Leminski, Catatau, p. 13.

92“(...) devemos ter sempre presente que a capacidade de nosso espírito é limitadíssima, e por isso devemos evitar ser tão presunçosos a respeito de nós próprios" (René Descartes, Princípios de Filosofia, p.93).

93 “Ora, os princípios que atrás expliquei são tão amplos e fecundos que atrás deles podemos deduzir muitas coisas que não vemos no mundo e até outras que nem numa vida conseguiríamos compreender com o pensamento" (René Descartes, Princípios de Filosofia, p.94).
} 
primeira. Inicialmente, estas suposições serão levantadas a partir do terreno metafísico preparado pelo filósofo na parte IV do Discurso do Método.

A começar, a ontologia cartesiana contém como principal sustentáculo o conceito de "uma substância cuja essência ou natureza [que] consiste apenas no pensar ${ }^{94 ،}$. Admite-se, por consequência desta postura uma distinção radical entre a natureza corpórea e a natureza pensante, cuja esta se torna mais fácil conhecer do que aquela. A ontologia cartesiana impõe como condição para o exercício do pensar a dúvida acerca das verdades. As verdades teriam como fator distintivo a sua clareza e distinção. Este exercício se restringe à alma ou tudo aquilo que pode ser chamado de "eu", como diz Descartes:

De qualquer maneira que esse eu, ou seja, a alma, por causa do qual sou o que sou, é completamente distinto do corpo e, também, que é mais fácil de conhecer do que ele, e, mesmo que este nada fosse, ela não deixaria de ser tudo o que é..$^{5}$

A ontologia cartesiana prescinde de demonstração que envolva as condições de existência da natureza corpórea. Logo, a existência se deve ao pensamento e, deste modo, tudo o que é exterior a ele pode ser falseado.

No que diz respeito à clareza e distinção de nossas ideias, a verdade corresponde à intersecção entre a clareza e distinção. Quer dizer, sem nenhum destes fatores, não há sequer a constituição de uma verdade ${ }^{96}$. Entre as verdades claras e distintas, o cogito é uma delas. O "eu penso, logo existo" seria uma certeza por si só, pois a princípio ela não necessita de condições corroborativas desta proposição. Mas, paradoxalmente, reside um problema nesta formulação: se é possível julgar como certo que as demonstrações feitas pela via de nossa razão são verdadeiras, no que consiste esta demonstração?

$\mathrm{Na}$ ontologia cartesiana, a natureza se divide na ordem do pensamento e na ordem da extensão. Entretanto, somente a natureza pensante - perfeição contida na sua totalidade em Deus - abrange em si as verdades claras e distintas. Para o homem ter acesso as estas verdades, ele depende sumamente da perfeição de Deus. Todavia, a

94 René Descartes, Princípios de Filosofia, p. 93.

95 René Descartes, Princípios de Filosofia, p. 93

96 “E, ao perceber que nada há no eu penso, logo existo, que me dê a certeza de que diga a verdade, salvo que seja muito claramente que, para pensar, é preciso existir, concluí que poderia tomar por regra geral que as coisas que concebemos muito clara e distintamente são todas verdadeiras, havendo somente alguma dificuldade em notar bem quais são as que concebemos distintamente" (René Descartes, Princípios de Filosofia, p. 94). 
imperfeição do homem, no âmbito do pensamento, se deve a sua capacidade de duvidar, arremata Descartes:

Depois, havendo refletido a respeito daquilo que eu duvidava, e que, por conseguinte, meu ser não era totalmente perfeito, pois via claramente que o conhecer é perfeição maior do que o duvidar, decidi procurar de onde aprendera o pensar em algo mais perfeito do que eu era; e descobri, com evidência, que devia ser de alguma natureza que fosse realmente mais perfeita $^{97}$.

O que torna, também, o homem limitado é o fato de ele estar na iminência da natureza pensante e da natureza corpórea. De forma alguma, a perfeição da natureza reside nos corpos, "consequência e dependência do menos perfeito" 98 . Retomando, a natureza de Deus possui todas as perfeições. A razão no homem é parte desta perfeição, que a torna como o seu atributo. Portanto, o que limita o uso da razão no homem é a sua dependência em relação à natureza corpórea.

\section{3) A luneta e a erva: dois paradigmas ontológicos distintos e inversos}

Nada obstante, não é apenas a dependência de nossa natureza - de caráter pensante - à natureza corpórea que limita o homem. O homem também se engana a partir da percepção pelos sentidos e também pela imaginação. Em especial, a imaginação - "maneira de pensar particular às coisas materiais, que tudo quanto não é imaginável lhes parece não ser inteligível" "99 - é o momento no qual fica mais evidente a dependência do pensamento em relação ao corpo. Como corolário desta dependência, a imaginação cria quimeras, característica fortemente presente no Catatau. Esta ilusão criada pela imaginação fica corrente no seguinte trecho:

A coisa arruína o olho, não volta mais à forma antiga, quantos vidros e lentes vai querer entre si e os seres? Um corpo é muito osso para um olho que quer crescer sem mãos para o confundir. Tem que ver como tem que ser, intervalos de ilusão de ótica para as evidências certas $(. . .)^{100}$.

Este trecho retrata o movimento inverso da ontologia cartesiana. A operação da razão diante da res estensa distancia-se do conhecimento claro e distinto desta res estensa. No Catatau, ver a natureza com lentes representa a asserção da natureza

\footnotetext{
97 René Descartes, Princípios de Filosofia, p. 94.

98 René Descartes, Princípios de Filosofia, p.64.

99 René Descartes, Princípios de Filosofia, p.66.

100 Paulo Leminski, Catatau, p.23.
} 
racional atribuída ao homem à natureza corpórea; no caso da relação de Cartesius com a natureza tropical, vê-la sob a perspectiva das lentes (ou da razão) é distanciar-se dela.

Em análise, como é possível demonstrar de maneira mais apurada a relação entre o uso da luneta com as categorias ontológicas da filosofia de Descartes? Leminski sintetiza esta relação no excerto seguinte: "E os aparelhos ópticos, aparatos para meus disparates? Este mundo é feito da substância que brilha nas estremas lindezas da matéria". ${ }^{101}$ Aqui, decerto, há alguns elementos da ontologia cartesiana a serem comparados com este trecho. A luneta, como instrumento ontológico, é a correção pela justa razão dos enganos pelas quais o homem está sujeito no que diz respeito ao conhecimento da natureza. A luneta, neste caso, também é um modo de conhecer a natureza pela explicação clara e distinta de seus elementos.

O conceito de substância, para Descartes, tem como referente a verificação da existência de uma coisa que existe por si, logo, não depende de outra coisa para existir. No entanto, pra Descartes não é possível para o sujeito apreender, pelo pensamento, a substância. O máximo que o pensamento consegue fazer é apreender os atributos, qualidades e propriedades da substância ${ }^{102}$. A luneta, então, representa o momento em que o pensamento consegue deduzir a existência de substâncias por meio de seus atributos, encontrando uma noção comum entre eles.

Entretanto, de maneira implícita, a luneta pode conceber a existência de atributos da substância corpórea. Conforme a regra I, da parte II do Princípio de Filosofia, Descartes assevera que "as razões que nos levam a conhecer com segurança que há corpos" tem como condição necessária a existência da "substância extensa [que chamamos] propriamente corpo ou substância das coisas materiais"103. A atividade do pensamento, metaforizada pela luneta, demarca a substância extensa através de grandezas como comprimento, a largura e a altura. O segundo fator de demarcação é a apreensão dos movimentos sensíveis das substâncias extensas. O terceiro fator,

101 Paulo Leminski, Catatau, p. 23.

102 Cf. A regra 56 en: René Descartes, Princípios de Filosofia, 1997, p.45-6: “A noção que assim temos de substância criada refere-se a todas da mesma maneira, isto é, tanto às que são imateriais como às corpóreas, porque para compreender as substâncias basta verificar que podem existir sem o auxílio de qualquer outra coisa criada. (...). É necessário, portanto, que possua alguns atributos que possamos notar; e qualquer um é suficiente para este efeito, porque uma das noções comuns é que o nada não pode ter nenhum atributo, propriedade ou qualidade. Por essa razão, logo que encontramos algum atributo podemos concluir que é o atributo de alguma substância, e que tal substância existe. 
conotado pelo brilho, encerra o movimento da percepção e demarcação da substância corpórea pelo pensamento, isto é, levanta-se como hipótese de que o brilho é o momento em que há clareza e distinção da própria extensão.

Em relação aos aparelhos ópticos, Descartes teve uma preocupação que o levou a reformulá-los. O filósofo tem a intenção de criar e projetar um aparelho óptico capaz de anular os efeitos da ilusão de óptica com maior precisão ${ }^{104}$. Transportando esta noção para uma ordem ontológica, seria uma maneira de observar com maior precisão os atributos da substância corpórea. No entanto, no mundo dos trópicos, a luneta não seria capaz de corrigir as ilusões de óptica, mantendo o sujeito pensante num estado de delírio, no qual as relações entre pensamento e mundo não se conectam de modo reto, claro e distinto. No apêndice do Catatau, Leminski adverte que "é um texto colocado sob o signo da Ótica, Descartes sendo um dos pais da Ótica como disciplina científica, parte da Física. Está cheio de anomalias óticas: refrações, difrações, desvios, que incidem sobre as palavras, as sentenças, a linguagem e a lógica." ${ }^{105}$ Portanto, foi visto que os "disparates" são as ilusões de óticas no sentido amplo descrito por Leminski e os aparatos ópticos representam a tentativa de corrigi-las; tentativa esta frustrada na relação entre Cartesius e a multiplicidade confusa e indistinta do novo mundo.

Por outro lado, a relação de Cartesius com este mundo se estreita com o uso de ervas alucinógenas, representando o contato mais puro, irracional e imediato com os elementos que compõe a natureza estrangeira, arremata Risério nesta citação:

\begin{abstract}
À maneira de Newton, Cartésio (Descartes) está sentado sob uma árvore em Vrijburg (Recife). Mas o que cai em sua cabeça não é a lendária maçã, e sim o coco de bicho-preguiça. A árvore é o posto de onde o filósofo observa a natureza tropical, fumando uma erva misteriosa (fuxopumo para viver), que lhe foi ministrada pelo enigmático Artyczewski, e contemplando a paisagem a lentes de luneta. Os "instrumentos" do filósofo parecem ter um significado bastante claro. A erva nativa que traga fala de um contato com o novo país. A luneta é seu oposto: "quantos vidros e lentes vai querer entre si e os seres?" Diante da nova realidade brasileira, Descartes, um dos pais da ótica, tenta racionalizar o que vê: "Medito uma medida para as mudanças deste mundo, onças, pares palmos e quintais, a entrarem por um vidro e saindo pelo outro". Mas o Brasil seiscentista baratina o filósofo: "E os aparelhos óticos, aparatos para meus disparates?" Desse modo, ao passo que o fumo é o signo de uma aproximação, a luneta, instrumento europeu, deixa-se ler como sinal de um distanciamento. Aqui, há, ainda, uma reflexão sobre o olhar. Ao filósofo interessa mais o "objeto-em-geral" que os seres individuais. Assim, Cartésio opõe a perfeição das figuras geométricas à imperfeição dos animais, "vítimas
\end{abstract}


das formas em que se manifestam". ${ }^{106}$

Deste modo, o "olho que cresce sem mãos para confundir o corpo" denota a ilusão da própria razão em conhecer um corpo clara e distintamente, sob a ausência dos sentidos. Para Leminski, neste excerto, ver a coisa como ela é significa conceber a existência da coisa sem a interferência da razão. A ilusão de ótica, por fim, representa parte da evidência das coisas e não uma contrapartida que deva necessariamente ser evitada. Portanto, a razão - à maneira de Leminski no Catatau - cumpre o mesmo papel da imaginação correlata ao pensamento cartesiano.

A imperfeição dos entes naturais dos trópicos se aproxima da percepção de Cartesius nos momentos do livro em que ele supostamente faz consumo de ervas alucinógenas. Enquanto a luneta é um instrumento que representa a tentativa inaudita de quantificar e categorizar os fenômenos e a percepção, o uso da erva faz com que a apreensão da natureza percorra o caminho inverso. A apreensão, nestes momentos específicos, não é um fato epistemológico - cujos conceitos têm a pretensão de dominar os fenômenos - mas sim um fato fenomenológico, cujo os entes naturais não se perfazem de acordo com conceitos previamente dados, mas aparecem imediatamente e sensivelmente à consciência, num gesto em que o "mundo vivido" se identifica com o mundo dos trópicos ${ }^{107}$. A luneta é um instrumento ontológico de objetificação da natureza, dos quais seus elementos ou seus entes são homogeneizados pelos conceitos. A erva, todavia, é um dispositivo de contato imediato e intuitivo do sujeito Cartesius, àquilo que outrora se chamava natureza.

Para Leminski, no Catatau, não há um conceito correlato a este estado aquém da objetividade constituída pela natureza pensante sobre a natureza corpórea. Até os elementos da linguagem, que tem como referente um recorte da natureza corpórea no Brasil (uma espécie de árvore, conforme o exemplo a seguir) se dissolve quando

106 Antônio Risério, Catatau: Cartesanato em Paulo Leminski, Catatau, p.229.

107 Merleau-Ponty mostra duas espécies de percepção, a saber, uma contida pela ciência clássica e a outra como imensurável por esta, mais fiel à experiência vivida de mundo: "Não diremos mais que a percepção é uma ciência iniciante, mas, inversamente, que a ciência clássica é uma percepção que esquece suas origens e se acredita acabada. O primeiro ato filosófico seria então retornar ao mundo vivido aquém do mundo objetivo, já que é nele que poderemos compreender tanto o direito como os limites do mundo objetivo, restituir à coisa sua fisionomia concreta, aos organismos sua maneira própria de tratar o mundo, à subjetividade sua inerência histórica, reencontrar os fenômenos, a camada de experiência viva através da qual primeiramente o outro e as coisas nos são dados, o sistema "Eu-Outro-as coisas" no estado nascente, despertar a percepção e desfazer a astúcia pela qual ela se deixa esquecer enquanto fato e enquanto percepção, em benefício do objeto que nos entrega e da tradição racional que funda" (Maurice Merleau-Ponty, Fenomenologia da Percepção, trad. Carlos Alberto Ribeiro de Moura. São Paulo: Martins Fontes, 1999, p.90). 
Cartesius inala a fumaça da erva alucinógena:

Aspirar estes fumos de ervas, encher os peitos no hálito deste mato, a essência, a cabeça quieta, ofício de ofídio. Cresce de salto o sol na árvore vhebehasu, que pode ser enviroçu, embiraçu, imbiroçu, aberaçu, aberraçu, inversu, inveraçu, inverossy, conforme as incertezas da fala destas plagas onde podres as palavras perdem sons, caindo em pedaços pelas bocas dos bugres, fala que fermenta. Carregam pesos nos beiços, pedras, paus, penas, mor de não poder falar: trazem bichos vivos na boca. Olho, penso esse bicho, o bicho me pisa na cabeça, o ventre pesa a carne, carcomido. ${ }^{108}$

Este é um exemplo claro da dissolução gradual do conceito da árvore nativa chamada embiriçu, pela dissolução da palavra. O consumo da erva é responsável por trazer ao Cartesius um "retorno às incertezas", que ocorre graças ao peso dos fenômenos vividos e experimentados pelo protagonista. Os conceitos de animal e vegetal, no mundo dos trópicos, se confundem nas alucinações de Cartesius, deixando ainda mais evidente os limites do conceito sendo estreitados pela primazia ontológica do mundo dos trópicos:

O silêncio eterno desses seres tortos e loucos me apavora. A árvore vhebehasu espreguiça à luz das suas moléstias venéreas a carne esponjosa, descascando verrugas na pedra-pomes; bafejando halos de pólen, espirais elásticas desgrudam membranas, pingando ranho, o pus ao gosto das sanguessugas, carunchando o fole dos favos em ogivas e meandros, fonte donde cipós passam a saliva que abastece o mercado de cupins $(. . .)^{109}$

Logo, sendo o Brasil o lugar em que o pensamento sistemático metaforizado pelos aparatos ópticos não se aplica, o ato de fumar ervas alucinógenas representa uma aproximação cognitiva de Cartesius em relação a multiplicidade natural do mundo dos trópicos. Aqui, a percepção e o sentir têm primazia ontológica sobre o pensamento e a lógica, pois estas operações do espírito não são, a princípio, capazes de apreender a exuberância deste novo mundo no qual Cartesius está inserido e, de alguma forma, desnorteado.

\section{Conclusão}

Foi demonstrado neste escrito como o pensamento cartesiano não detém de uma adequação lógica e epistemológica para a constituição de um entendimento acerca dos fenômenos ocorrentes no Brasil, segundo o Catatau. Entretanto, esta não é a única

108 Paulo Leminski, Catatau, p.17.

109 Paulo Leminski, Catatau, p. 17. 
leitura possível do livro. O texto de Leminski trata de diversos temas, históricos e políticos. Na etapa da pesquisa do livro, ainda não é certo dizer se há uma linha de pensamento único capaz de esgotar os limites interpretativos. Outros temas também são postos, tais como a ditadura civil-militar que o Brasil passou na década de 60 e 70, como também o carnaval. Neste caso, Leminski parece ter a intenção de descrever, com todos os seus pormenores e pelo uso não raro de metáforas, a realidade brasileira; realidade esta que está para além da apreensão definitiva que os conceitos podem trazer.

Para Paulo de Toledo, o Catatau é uma narrativa que se desenvolve a partir de dois planos temporais. O primeiro plano - presente da narrativa - se manifesta pelo solilóquio de Cartesius que perambula pelo Brasil holandês do século XVII. O segundo plano temporal é o presente do próprio Leminski, em plena ditadura militar. Em cada plano temporal que se perfaz implicitamente no livro, há uma indagação mordaz no presente da narrativa, Cartesius experimenta a dissolução do pensamento ocidental na experiência brasileira. Por conseguinte, Cartesius desloca-se do seu tempo para o presente do escritor, descrevendo a tortura e a crueldade pelas quais passavam os dissidentes do regime militar. Eis aqui um relato dos inquéritos provenientes da época:

\footnotetext{
Maltratado que nem cavalo de exu, apanha mais que cachorro de bugre, mais bem apanhado que arara caída do pau! (...) Me enfiam um trabuco goelas abaixo, confesso tudo e ainda reclamam do sotaque! ${ }^{110}$
}

Sem fazer uma análise das referências à ditadura militar presente no Romanceideia, Leminski sutilmente descreve as experiências horrendas dos inquéritos policiais, mostrando de tal forma o seu posicionamento quanto ao regime. Contudo, pode-se questionar se o Leminski pretendia relacionar o seu presente com o presente da narrativa.

Se ler o Catatau pressupondo um pensamento único que serviria de chave de leitura para a obra, é possível fazer esta relação. Caso contrário, o texto parece ser desconexo e sem uma cadeia lógica de argumentos que perfazem o enredo narrativo. Tanto a forma quanto o conteúdo não se mantém, havendo várias quebras de sentido e mudanças bruscas de temática, indo desde a descrição de fatos históricos e míticos da antiguidade até fatos contemporâneos, como o supracitado exemplo da ditadura. Logo, a hipótese é: o fundamento de leitura do Catatau exige do leitor a dissolução das categorias do pensamento para acompanhar toda a experiência brasileira sob a 
perspectiva europeia; e jamais esta experiência abandona a história, independente dos diversos planos temporais que se materializam no interior do livro.

\section{Referências}

ARANTES, Paulo. Sentimento da dialética na experiência intelectual brasileira. São Paulo: Paz e Terra, 1992.

DESCARTES, René. Discurso do Método in: Os pensadores. Trad.: Enrico Corvisieri. São Paulo: Nova Cultural, 1999.

DESCARTES, René. Princípios da Filosofia. Trad.: João Gama. Lisboa: Edições 70, 2003.

GAUKROGER, Stephen. Descartes: uma biografia intelectual. São Paulo: Editora Contraponto, 2003.

LEMINSKI, Paulo. Catatau: um romance-ideia. São Paulo: Iluminuras, 2010.

LEMINSKI, Paulo. Envie meu dicionário: Cartas e Alguma Crítica. São Paulo: Editora 34, 1999.

MERLEAU-PONTY, Maurice. Conversas - 1948. Trad.: Fábio Landa \& Eva Landa. São Paulo: Martins Fontes, 2004.

MERLEAU-PONTY, Maurice. Fenomenologia da Percepção. Trad.: Carlos Alberto Ribeiro de Moura. São Paulo: Martins Fontes, 1999.

SCHWARZ, Roberto. Ideias fora do lugar in: Ao Vencedor, as Batatas. São Paulo: Duas Cidades, 1992. 